\title{
Re-orchestrating Game Drama: The Immersive Experience of Dynamic Music in Video Games
}

\author{
Hans-Peter Gasselseder \\ University of Salzburg \\ Schmiedberg 2, A-4201, Gramastetten \\ Austria \\ maestroso@gmail.com
}

\begin{abstract}
Non-linear storytelling environments take us one step closer towards immersive experiences while relying heavily on the emotional congruency of the presented stimuli as a function of user action. Describing the drama of a given narrative framework, dynamic music scores also act adaptively as an individual component of perception and behaviour related phenomena of the player. Within the outlined context, a pilot study was conducted to explore imaginary and sensory immersion, suspension of disbelief, involvement, flow, spatial presence self location, possible actions as well as emotional valence and arousal in the context of dynamic and non-dynamic music in an actionadventure video game, while at the same time considering decoding skills and intensified emotional involvement in trait musical empathy and tendency for immersion. 60 subjects answered self-report questionnaires of experiential states each time after playing the game 'Batman: Arkham City' in one of three conditions accounting for 1) dynamic music, 2) non-dynamic music/low arousal potential and 3) non-dynamic music/high arousal potential, in this way manipulating affective arousal, structural-temporal alignment and emotional congruency of non-diegetic music separately. Whereas imaginary aspects of immersive presence are systemically affected by the presentation of dynamic music, sensory spatial aspects show higher sensitivity towards the arousal potential of the music score on which it is argued that a compatible integration of global and local game goals contributes to a motivational-emotional reinforcement that can be gained through musical feedback. Investigating the perceived drama related interactive qualities of dynamic music in the likes of a Theory of Mind approach, different layers of virtual mind sets between the player, avatar and game environment moderate a continuous regulatory modulation of emotional response, which by indications of the gathered data, might open the door to a decrease of post-game aggression achieved by contextual effects of dynamic music.
\end{abstract}

Dynamic music. Game audio. Immersion. Presence. Absorption. Flow. Music. Emotion. Human-Computer Interaction. Music Drama.

\section{INTRODUCTION}

Non-linear storytelling environments as found in current generation video games take us one step closer towards immersive experiences while relying heavily on the structural and expressive congruency of the presented stimuli. By offering an interactive environment that requires corresponding musical drama, video games form a valuable tool in research on the relation of music, drama, cognition, and emotion as a function of user action.

In order to confront the challenge of a non-linear time domain, game scores increasingly implement procedural techniques, popularly referred to as 'dynamic music', aiming to react to changes in the game environment as well as changes on the user side musically. According to this, proceduraldynamic techniques can also be distinguished in terms of their narrative-dramaturgic functions (Gasselseder \& Kallionpää 2012). Whereas narrative functionalized horizontal sequencing retrieves music cues which correspond to a given scene, the dramaturgic functionalized vertical reorchestration adds and removes separate instrument layers in accordance to the portrayed intensity of the scene and by doing so adapts its content and expressive arousal characteristics to the actions of the player. Thus a dynamic music score cannot only be seen as a means of describing the drama of a given narrative framework but in addition as an individual component of perception and behaviour related phenomena of the player.

Despite its growing recognition by users as well as developers and a body of work involving prototyping as well as descriptive approaches on procedural mechanisms, the hypothetical reasoning 
of immersive functions of dynamic music has not been empirically assessed. On this account the present paper sets out to expand the ludomusicological discipline from a cognitive narratological and experimental psychological perspective by integrating theoretical as well as empirical data gathered in a pilot study examining the hypothetical basis of immersive functions of dynamic music for the first time.

\section{MUSIC AND IMMERSIVE PRESENCE}

Different views and understandings of the term 'immersion' call for an integrated approach that considers imaginary aspects in absorption, suspension of disbelief and involvement as much as allowing for sensory-spatial aspects in flow, selflocation and interactive actions. The multiconstruct 'Immersive Presence' (Gasselseder 2012), which aims to consolidate the aforementioned nonmediated phenomena within a unified framework, is adapted to outline the musically supported experience of absorption within multisensory media environments such as video games. In this connection immersive experiences are understood as a result of the juxtaposition of expected and received sensory contents of the environment (cf. Popper \& Fay 1997, Bruner \& Postman 1949). Characterized by superior temporal resolutions of expressive qualities, sonic dimensions, like music, are highly suitable to take over other senses during the initial direction of selective attention towards congruent perceptions (cf. Spence \& Driver 1997, Maasø 2000). Thus, the associative situationspecific and expectation driven evaluative functions of music influence the scenic interpretation in accordance to audio-visual correspondence as well as visual perception (cf. Boltz et al. 1991, Cohen 2001, Petrini et al. 2011). When expressive qualities of music stimuli become salient, multisensory expectations on emotional congruency towards the environment, termed hypotheses of perception, are formed. If the multisensory stimuli indeed match the hypotheses of perception in a congruent sense, an intensified allocation of attention to the media content arises (cf. Gasselseder 2012). Consequently the reference frame of extramedial processed, musicbound associated contents of schemes [e.g. motives for success or failure] is attributed towards the media space in a process termed 'situational context localization' which leads to 'imaginary immersion' (cf. Ermi \& Mäyrä 2005, Wirth et al. 2007, Gasselseder 2012). An extramedial processing of active schemes implicates a conscious integration of associated contents within the situational context of the media reception. Are levels of music-induced emotional arousal increasing in proportion to arousal induced by the media presentation, the extramedial frame, with its associated contents of schemes, is shifted into the intramedial space. The resulting emotional involvement pertains the impression of an inclusion in the meaning of the expressive accent structure of the media presentation and leads to the final state of presence, a state of consciousness characterized by the physical 'self localisation' into the media environment and its elevated perception of 'possible actions' herein (cf. Wirth et al. 2007, Gasselseder 2012). Therefore the associated contents of schemes are unconsciously attributed within the situational context of the media reception, giving rise to intramedial localisation. The situational context model, as it is outlined here, describes the mediated perspectivation of the situational characteristics represented by the immersive media format and its associated meanings, allowing for a segregation of perceived relations within the narrative (cf. Bruner 1986, Zwaan 1999, Gasselseder 2012).

\section{METHOD}

A pilot study was conducted to explore imaginary and sensory immersion (iGEQ, IJsselsteijn et al. 2007), flow (iGEQ), spatial presence self-location (MEC-SPQ, Vorderer et al. 2004), possible actions (MEC-SPQ) as well as emotional valence and arousal (EMuJoy, Nagel et al. 2007) in the context of dynamic and non-dynamic music in an actionadventure video game. 60 subjects [23 female, 37 male] aged $18-30$ years $[M=23.72, S D=3.4]$ were asked to answer self-report questionnaires of experiential states each time after playing the video game 'Batman: Arkham City' (Rocksteady 2011) for 10 minutes in one of three randomized conditions accounting for [1] dynamic music, [2] non-dynamic music/low arousal potential and [3] non-dynamic music/high arousal potential, in this way manipulating affective arousal, structural-temporal aspects and emotional congruency of non-diegetic game music separately.

\subsection{Subjects}

Subjects spend on average 2.37 hours [ $S D=1.68$ ] at 2.81 days per week [SD=1.78] with playing digital games. 56.8 per cent of responses on preferred game genres related to narrativedramaturgic elements found in action-adventure game titles. None of the included subjects had played the stimulus game 'Batman: Arkham City' (Rocksteady 2011) nor its predecessor 'Batman: Arkham Asylum' (Rocksteady 2009) before. All included subjects were well familiar with the main protagonist 'Batman' and hold a neutral or positive attitude towards the characters' other media outings. All subjects included in the study finished the presented game segments successfully and did not identify the experimental manipulation of music accompaniment.

\subsection{Materials}

Balancing the compromise between a controlled experiment under steady conditions and a natural environment of virtual interaction as experienced in open world games, the map segment 'Penguin Museum' of the critically acclaimed 3rd person action-adventure video game 'Batman: Arkham City' (Rocksteady 2011) was chosen for its guided navigation, task coordination focusing in a closed manner on specific goals and story paths while providing a wide and rich terrain to be discovered 
by the player. The players' task is to string henchmen along from following escaped hostages within a timeframe of 10 minutes displayed as a countdown in the avatars cowl and in this way providing sufficient time for the rise of immersive experiences (cf. Örtqvist \& Liljedahl 2010).

Arkham City's orchestral music score by Nick Arundel and Ron Fish makes use of a horizontal sequencing mechanism mainly reflecting calm and confrontation situational changes in the narrative by musical expression characteristic to low and high arousal potential (see Juslin \& Laukka 2003, Wassermann et al. 2003, Juslin \& Lindström 2011). In addition a vertical re-orchestration mechanism reflects task process in the drama of the game presentation by adding and removing four orchestral stems to the mix relative to actions and performance of the player. For example, if the avatar is surprised by an attack of henchmen, the music changes immediately to the orchestra tutti heard in the full mix. However, if the avatar knocks henchmen unconscious without being noticed by others, the orchestration is reduced to strings only and additional layers of brass and percussion will only be introduced when further henchmen are attacked in secret.

\subsection{Instruments}

EMuJoy: The emotion software measurement instrument 'EMuJoy' (Nagel et al. 2007) operationalizes the circumplex model of emotion (Russell 1980) in an easy to understand, intuitive visual interface by presenting the emotional space as a coordinate system between degree of valence [pleasure-displeasure, $\mathrm{X}$-axis] and arousal [Y-axis]. Ratings are given by moving a cursor and pressing a controller button when a corresponding position has been found in the emotional space. When testing for reliability and validity, the instruments" authors find high re-test and construct correlations of about $r>0.8$ as well as high consistency between continuous and distinct measures at the end of stimulus presentation. In the context of the present study the application of EMuJoy is limited to distinct measures before and after game presentation due to distortive effects of diverted attention and other sources potentially interfering with the experience of immersion

iGEQ: Two dimensions taken from the 'In-Game Experience Questionnaire' (IJsselsteijn et al. 2007) were used to measure subjects' experience of immersion and flow while playing the game. Each dimension contains a pair of items rated on a Likert-type scale scored from 0-4. Good internal consistencies of about $\alpha=.80$ attest reliable measures for the German translation in use (Klimmt et al. 2010) on the selected dimensions. The dimension 'Imaginative and Sensory Immersion' aims to measure narrative elements and associated empathic responses while also considering sensations caused by the audio-visual quality and style of the game presentation. The dimension 'Flow' derives its name from Csikszentmihalyis' (1975) popular construct describing a holistic mental feeling of absorption when merged in performing an activity and its intrinsic gratification, though it has been found that iGEQ item formulations primarily address autotelic experiences (cf. Poels et al. 2007, Gasselseder 2012).

MEC-SPQ: Three dimensions taken from the 'MEC Spatial Presence Questionnaire' (Vorderer et al. 2004) add to the measurement of immersive presence. Each dimension contains 4 items presented in randomized order and rated on a Likert-type scale scored from 0-4. Studies undertaken by the instruments' authors show good internal consistencies of the chosen dimensions in the range from $\alpha=.80$ to $\alpha=.92$ as well as construct validity of about $k>.70$. The dimension 'self location' refers to a sense of physical projection when interacting with the game. Herein the dimension 'possible actions' measures perceived interactive qualities. A dimension more akin to the concept of absorption (Diderot 1757), 'suspension of disbelief', draws on the cogency of the medium, thus serving as a possible prerequisite of immersive experiences. MEC-SPQ-suspension of disbelief item operationalization appears to refer on the plausibility of media presentations, in this way accommodating links to imaginary immersion (cf. Gasselseder 2012).

\subsection{Procedure}

Game contents are displayed in 30 to $40 \mathrm{~cm}$ distance from subjects' faces on a 15.6" notebook running at $1366 \times 768$ pixels, $32-b i t, 60 \mathrm{~Hz}$ in the games' second highest graphic settings. Sound is provided through closed stereo headphones [AKG K270 Studio] at 30 per cent volume on an audio interface [MOTU $828 \mathrm{mk} 1$ ], which is connected to a separate control system [Apple MacBook Pro 6.1]. In order to mix in-game sound-fx and A-weighted volume matched pre-recorded music tracks for non-dynamic music, sound-fx contents are fed to the monitoring input of a software sequencer [Apple Logic Pro] set at 128 buffer size.

Prior testing, subjects get acquainted with the game mechanics and the emotion software measurement instrument 'EMuJoy' (Nagel et al. 2007) during a 30 minutes training session. Before starting the game, subjects are asked to rate their current emotional state on EMuJoy. Whenever subjects are ready, pressing the corresponding controller button triggers the start of the game segment. The game segment is presented in three sessions of 10 minutes length, each reflecting one out of three music modalities contrasting dynamic/non-dynamic mechanisms and arousal potential characteristics in randomized order. At the end of the game segment, an animation of 5 seconds length signals successful completion of the session which marks the point when sound is faded out gradually. Subsequently subjects are asked to give a rating on EMuJoy and to complete measurements on the 'iGEQ' and 'MEC-SPQ' instruments. 


\section{RESULTS}

As depicted in table 1, the music score of the game systematically affected both imaginary and sensory-spatial aspects of immersive presence.

Table 1: Mean rankings (Friedman-Test) of ratings on dimensions of immersive presence

\begin{tabular}{|l|c|c|c|}
\hline & \multicolumn{3}{|c|}{ Music condition } \\
\cline { 2 - 4 } & Dynamic & $\begin{array}{c}\text { Non- } \\
\text { Dynamic } \\
\text { low AP }\end{array}$ & $\begin{array}{c}\text { Non- } \\
\text { Dynamic } \\
\text { high AP }\end{array}$ \\
\hline $\begin{array}{l}\text { Imaginary \& } \\
\text { Sensory } \\
\text { Immersion (iGEQ) }\end{array}$ & $2.23^{*}$ & 1.87 & 1.90 \\
\hline $\begin{array}{l}\text { Suspension of } \\
\text { Disbelief (MEC-SPQ) }\end{array}$ & $2.23^{(*)}$ & 1.89 & 1.88 \\
\hline $\begin{array}{l}\text { Flow (iGEQ) } \\
\text { Self Location } \\
\text { (MEC-SPQ) }\end{array}$ & 1.88 & $2.23^{*}$ & 1.88 \\
\hline $\begin{array}{l}\text { Possible Actions } \\
\text { (MEC-SPQ) }\end{array}$ & 1.96 & 1.83 & $2.21^{(*)}$ \\
\hline
\end{tabular}

'AP' denotes arousal potential. Asterisks in brackets ${ }^{(*)}$ denote approached significance.

In particular the dimension 'imaginary and sensory immersion" showed significantly higher ratings when playing the game with dynamic music, $\chi^{2}(60)=6.23, p=.04$, while 'suspension of disbelief' closely approached significance, $\quad \chi^{2}(60)=5.14$, $p=.07$. The sensory-spatial aspect 'flow' showcased significantly higher sensitivity towards the low arousal potential of the non-dynamic music score, $\chi^{2}(60)=5.88, p=.05$, whereas ratings on 'perceived possible actions' approached significance when non-dynamic music with high arousal potential was presented, $\chi^{2}(60)=5.22, p=.07$. No differences in 'self-Iocation' were observed in any of the experimental conditions, whereas a significant correlation appeared when the game had been played with dynamic music, $r=.37, p=.00$, and nondynamic music with low arousal potential, $r=.32$, $p=.01$. In contrast to these results, pre-post measures of arousal correlated to 'self-location' only when dynamic music was present, $r=.31$, $p=.01$. Though ratings on arousal didn't differ between low and high arousal potential conditions, subjects attributed significantly more positive valence to experimental conditions characterised by music with high arousal potential, $F(59)=3.83$, $p=.05$.

\section{DISCUSSION}

This paper has provided first empirical evidence of subjects' enhanced immersive experiences when being presented with procedural audio solutions integrated in a video game. Still, the question remains if the effects of dynamic music are to be attributed to a mechanism akin to the mediated perspectivation as described in the situational context model. Indeed, subjects report higher imaginary and sensory immersion when playing the game accompanied by dynamic music. Similar tendencies can be observed in reports of suspension of disbelief, even though musically expressed arousal potential seems to influence ratings stronger than when looking at imaginary and sensory immersion. Whereas dynamic music and non-dynamic music with high arousal potential lead to significant different ratings on imaginary and sensory immersion, these effects diminish when considering suspension of disbelief. In contrast to iGEQ-dimensions, item wording of MEC-SPQsuspension of disbelief refrains from a distinction of narrative and sensory aspects of gameplay experience. While this might be a valid explanation for a slightly weaker influence of arousal potential in the case of imaginary and sensory immersion, it also underlines the importance of expressive characteristics in dynamic music, suggesting interactional effects with perceived degrees of realism in other modalities such as graphics, sound-fx and the naturalness of interaction (cf. Witmer \& Singer 1998). If dynamic music achieves a higher influence on the narrative-dramaturgic contextual localisation, this effect seems to be less constituted by stringing together music cues with stable emotional arousal potentials than rather their progressive modulation corresponding to the scene.

In contrast to a more abstract narrative understanding, situational context components, such as 'flow', are thought to be mostly sensitive to sensory inputs attributed to the surface of the media presentation. In the present study perceptual realism, a concept important to the formation of presence, also seems to have played a role in higher ratings on flow when playing with nondynamic low arousal potential music compared to its high arousal and dynamic counterparts (cf. Witmer \& Singer 1998). Whereas the elevated volume in high arousal potential music overshadows sound-fx, low arousal potential music brings along a reduced music scenery allowing for sound-fx to be perceived more similarly to a feedback function subjects have become accustomed with in the real world. In receiving feedback to set actions as well as enhancing a sense of control of action and environment, two fundamental components of the original flow-model are met by the role assumed in sound-fx (cf. Csikszentmihalyi 1991). Consequently sound-fx achieve a moment-to-moment synchronisation of player skills and task difficulty as experienced in successful or failed movements in gameplay. This interpretation seems less surprising when taking into account prior studies on game audio that identify sound-fx as supportive to the experience of flow (cf. Grimshaw et al. 2008, Gasselseder \& Dobler 2009) and music as obstructive in challenge based game genres (cf. Yamada et al. 2001, Cassidy \& MacDonald 2010). On the other hand, these results stand in contrast to a study performed by Sanders and Cairns (2010) who bring music in connection with subjects' positive experiences and 
altered sense of time while solving puzzles. Moreover, if flow is to be distinguished from presence-like states linked to perceptual realism, its evolvement should depend on factors stimulating autotelic experiences, such as multisensory sources of feedback. Contextualising this within a narrative framework in video games can be a challenging task. In terms of goal definitions in flow typology, the dramaturgic tie of the game segment used in the present study primarily addresses the rescue of hostages and the vigilante fight of criminals. As such suggesting a global goal to players, it stands in stark contrast to local goals as demanded in gameplay, which spans from hiding, distraction to intimidation of villains. Thus, a constant readjustment of goals as suggested by a changing dramaturgic background might hinder the centring of attention as well as a fluid course of action. Within the mix of concurrent goals at a global perspective of narration and a local perspective of task performance, music traditionally takes up the expressive connotations of global goals and their development in drama, instead of giving direct feedback to each of the players' movements. In this way, music mainly expressively operationalizes relational characteristics in the virtual environment to the avatar, whereas its functionalization to the player is limited to structures of meaning (cf. Tan 1996, Gasselseder 2012). Consequently, new ways of embedding global and local goals in a compatible manner will have to be found in order to assure accessibility through coherent musical connotations. Novel game designs employing gradual changes from narration-driven, interactive cinematics to performance-focussed tasks, as seen in Heavy Rain (Quantic Dream 2010), promise a first step towards the fulfilment of desiderata asking for an uninterrupted, task-transcendent fluid game experience.

Likewise to 'flow' the dimension 'self location' is assumed to have links to perceptual realism. In addition several studies have identified a correlation between arousal and presence/selflocation. Interestingly, the present study did not find any differences in subjects' ratings on self-location when presented with dynamic/non-dynamic and low/high arousal potential modalities. One might assume that music doesn't affect the experience of self-location. Alternatively, a more obvious explanation might relate to the small screen size the game was played on as well as different qualitative modes of presenting visual, auditory, and tactile channels of multisensory stimuli, hereby reducing congruency of stimulus features (cf. Lombard et al. 2000, Freeman \& Lessiter 2001, Wirth \& Hofer 2008). Still, effects resembling the influence of sound-fx on perceptual realism can be observed in correlations between arousal and ratings on self-location when playing with dynamic music and non-dynamic music with low arousal potential. Even more interestingly, correlations between pre-post measures of arousal and selflocation can be found only in dynamic music presentations. Pre-post measures are assumed to be more sensitive to in-game modulations of arousal induced by a constant change of dramaturgic context reflected in dynamic music. This indicates a covarying influence on the correlation of arousal and self-location when playing with dynamic music, albeit without any significant deviations of arousal after gameplay. In light of the result pattern obtained from imaginary components [imaginary and sensory immersion, suspension of disbelief] and the aforementioned technical limitations possibly affecting ratings on self-location, dynamic music might be put in use as a protective factor of regulating emotional experiences in the context of arousal correlates in temporary aggressive tendencies of behaviour after gameplay (cf. Anderson et al. 2010, Gasselseder 2012). Due to the fact that dynamic and nondynamic music implementations didn't differ in subjects' reports of self-location, one presumes a combined effect of dynamic music and accentuations of sound-fx, which will be a subject of further investigations.

In accordance to prior studies, the dimension 'perceived possible actions' seems to be more sensitive to the high arousal potential variant of non-dynamic music (cf. Ravaja et al. 2004, Freeman et al. 2005). Contrary to expectations, the present study demonstrates this sensitivity rather in ratings on valence than in arousal. Subjects experience non-dynamic music with high arousal potential more positively than when playing with music characterized by low arousal potential. A possible explanation for this can be seen in what Stevens and Raybould (2012) recognize as 'Fiero' within the context of video games, an emotional state brought about by overcoming obstacles and providing positive reinforcement to the player. Given that recency effects significantly influence retrospectively reported experiences, the importance of consistent modes of completing a game segment cannot be emphasized enough (cf. Atkinson \& Shiffrin 1968). Whereas most research done on video games doesn't take into account the successful completion of levels that form the basis of stimuli under investigation, the present study decisively included an animation signalling success and providing positive feedback after completing the game segment. This feedback is transported musically only under conditions of dynamic music, while non-dynamic music continues to accompany in its predefined arousal potential characteristics. Being an important source of pleasure or 'Fun', fiero will mostly stand out when high arousal potential characteristics meet the positive reinforcement implied by the visuals (cf. Koster 2005). When analysing the expressive parameters of music separately, the high arousal potential condition seems to display higher accordance to the emotion category 'Fun' than their low arousal potential or dynamic music counterparts, thus, providing an explanation of higher ratings on valence/pleasure after having completed the game segment (cf. Juslin \& Lindström 2011). In line with a rather young research direction investigating the effects of picture on music, this interpretation of results demonstrates how visual-narrative elements could alter the meaning of music in a mood congruent manner of emotion induction by the interaction of multisensory stimuli (cf. Ebendorf 
2007, Boltz et al. 2009, Moore 2010). Conversely, future studies will have to check for effects on positive valence when game segments are not completed successfully while being accompanied by congruent music stimuli.

In recapitulating and expanding the theoretic framework the comparison of expected and received sensory contents implies a narrowed range of media reception that focuses on basal snippets of audio-visual congruency (cf. Bruner \& Postman 1949, Spence \& Driver 1997). While the first stage of reception concerns the visual localization of auditory sources within the media context, its relevance is expanded by allocating attention to congruent perceptions of picture and sound according to expectations. Structural as well as expressive features of music cause a retrieval of schemes in function to the scene. Its consistent combinations of expressive parameters relate to sensory as well as narrative abstracted sources and take part in directing attention (cf. Boltz et al. 1991). Rhythm in music, editing, and cinematography, musical legato or staccato in low versus high arousing scenes form examples of culturally established conventions of negotiating individually valid, connotative meanings as well as herein expressed accentuations of structure and emotion of the portrayed contents (cf. Gaver \& Mandler 1987, Magliano et al. 1996, Vitouch 2001, Wingstedt et al. 2008). Thus, inferences to scenic contents are to be understood as a predominantly unconscious reception of corresponding expressive parameters, which find entrance into the situational context model by defining relational characteristics of the portrayed events (cf. Barsalou et al. 1993, Zwaan 1999, Zbikowski 1999). Having reached this stage of perspective, an integration and elaboration of perceived contents leads to empathic reenactments analogues to salient motivations and patterns of behaviour.

Relational attributes, as described in the case of global and local goals and their functional relevance in gameplay, also allow for a segregation of interactive qualities of dynamic music. In the likes of a Theory of Mind approach, the 'Relational Environment Model of Interaction in Digital Imaginary, REMIDI' (Gasselseder 2012) defines parallel running layers of relational attributes as virtual mind-sets, which describe different perspectives of communicative structures and attitudes between environment [inter-], avatar [intra-], and player [introrelation]. Connotative references in music are assumed to influence relational attributes mainly on inter- and intrarelational layers where position in the field of action, attitudes and relations between characters in the environment [inter] are negotiated whilst handing over the resulting dispositions, views and situational positioning of portrayed dramatis personae to a separate perspective of the avatar [intra]. Posing a question about inter-relational mind-sets might involve how characters act, effect and understand each other within the realm of the narrative. Following this reasoning, a question about intra-relational mind-sets might ask how other characters within the narrative realm affect the avatar character and how the avatar is thought to understand those external characters in turn. Musical codes and acoustic-structural features are assumed to contribute to the direction of selective attention towards relational structures as well as the formation and recall of associations in a process analogous to the situational context model. Applying this kind of thinking on the data obtained in the present study, for example, intentions between characters are described as 'multifaceted' [interrelational] according to subjects' ratings on imaginary and sensory immersion item wordings when dynamic music is present. In ratings on 'suspension of disbelief' intentions between characters and avatar are operationalized in stronger 'credibility' [intrarelational] when gameplay is accompanied by dynamic music. In contrast, sensory-spatial components largely affect introrelational mind-sets that form the basis of communicative structures between the avatar and player. In line with this, a preceding qualitative study employing focus interviews on game audio dimensions found sound-fx more closely related to introrelational attributions that, for the most part, result in more frequent reports of competency in avatar-player interaction and lower ratings on difficulty in environment-avatar-player interactions (cf. Gasselseder \& Dobler 2009). In this sense, REMIDI assumes that subjects are capable of simulating different relational perspectives when approaching interactive media formats, therefor perceiving virtual environments from several vantage points, which can, but necessarily don't have to, culminate in a direct line of communicative messages from inter- over intra- to interrelations. Utilizing dedicated measures, future work on REMIDI promises to systematically uncover and categorize narrative-dramaturgic functions of audio modalities in video games.

In the context of procedural aesthetics players experience immersive presence and shape these experiences through individual manifestations of meaning. Still, many questions concerning the psychological effects of dynamic music remain unanswered, such as indications of different trait music drama apprehension and its connection to immersive tendency (cf. Gasselseder \& Dobler 2009 Gasselseder 2012). The resulting balancing of individual disposition, interpretation and behaviour within the virtual environment acts as an additional influence on the situational context model. By this means individualising the context of the medium in terms of relational attributes to the environment, the recent developments of music drama in procedural game music promise a new kind of cognitive and emotional involvement that is to be kept in sight by psychological research disciplines. Given the vast field of possible applications announcing enhanced humancomputer interactions, it is to be hoped that procedural audio will gain its well-deserved spotlight in a manner that goes beyond a raison d'être as expressed in the following quote based on an excerpt of Madame de Staël's novel 'Germany': 
"Those who danced where thought to be quite insane by those who could not hear the music." (de Staël in Carlin 1997)

\section{REFERENCES}

Anderson, C. A., Shibuya, A., Ihori, N., Swing, E., Bushman, B., Sakamoto, A., Rothstein, H.R. \& Saleem, M. (2010) Violent Video Game Effects on Aggression, Empathy, and Prosocial Behavior in Eastern and Western Countries. A Meta-Analytic Review. Psychological Bulletin, 136(2), pp.151-173.

Atkinson, R.C. \& Shiffrin, R.M. (1968) Human Memory. A Proposed System and Its Control Processes. In Spence, K.W. \& Spence, J. T. (eds): The Psychology of Learning and Motivation. Volume 2. Academic Press, New York, NY.

Barsalou, L. W. (1993) Flexibility, structure, and linguistic vagary in concepts. Manifestations of a compositional system of perceptual symbols. In Collins, A. F., Gathercole S. E., Conway, M. A. \& Morris, P. E. (eds): Theories of memory. Lawrence Erlbaum Associates, Hillsdale, NJ, pp.29-101.

Boltz, M. G., Ebendorf, B. \& Field, B. (2009) Audiovisual interactions. The impact of visual information on music perception and memory. Music Perception, 27(1), pp.4359.

Boltz, M., Schulkind, M. \& Kantra, S. (1991) Effects of background music on the remembering of filmed events. Memory \& Cognition, 19(6), pp.593-606.

Bruner, J. (1986) Actual Minds, Possible Worlds. Harvard University Press, Cambridge, MA.

Bruner, J. S. \& Postman, L. (1949) On the perception of incongruity. A paradigm. Journal of Personality, 18, pp.206-223.

Carlin, G. (1997) Brain Droppings. Hyperion Books, New York, NY.

Cassidy, G. G. \& MacDonald, R. A. (2010) The effects of music on time perception and performance of a driving game. Scandinavian Journal of Psychology, 51, pp.455464.

Cohen, A. J. (2001) Music as a source of emotion in film. In Juslin, P. \& Sloboda, J. (eds), Music and Emotion. Oxford University Press, Oxford, UK.

Csikszentmihalyi, M. (1975) Beyond boredom and anxiety. Experiencing flow in work and play. JosseyBass, San Francisco.

Csikszentmihalyi, M. (1991) Flow. The Psychology of Optimal Experience. Harper and Row, New York.

Diderot, D. (1757) Le fils naturel ou les epreuves de la vertu. Comedie en cinq actes, et en prose. http://books.google.co.uk/books? id=ansHAAAAQAAJ (retrieved 16 June 2013).

Ebendorf, B. (2007) The Impact of Visual Stimuli on Music Perception. Senior Thesis at Haverford College, Haverford, PA, USA.

http://thesis. haverford.edu/dspace/handle/10066/996 (retrieved 16 June 2013).

Ermi, L. \& Mäyrä, F. (2005) Fundamental Components of the Gameplay Experience. Analysing Immersion. In de
Castell, S. \& Jenson. J. (eds), Changing Views - Worlds in Play.

http://www.uta.fi/ tlilma/gameplay experience.pdf (retrieved 16 June 2013).

Freeman, J. \& Lessiter, J. (2001) Here there and everywhere. The effects of multi-channel audio on presence. In Proceedings of the Seventh International conference on Audio Display, Helsinki, Finnland, pp.231234.

Freeman, J., Lessiter, J., Pugh, K. \& Keogh, E. (2005) When presence and emotion are related, and when they are not. Presence 2005. The 8th International Workshop on Presence. University College London, London, UK. http://www.temple.edu/ispr/prev conferences/proceeding s/2005/presence2005.pdf (16 June 2013).

Gasselseder, H.-P. (2012). Re-Orchestrating Game Drama. The Immersive Experience of Dynamic Music in Video Games. Diploma Thesis at the Department of Psychology, Paris-Lodron University of Salzburg, Austria.

Gasselseder, H.-P. \& Dobler, V. (2009) SPIELfilmTon [GAMES-film-Sound]. Unpublished research paper at the University of Salzburg.

Gasselseder, H.-P. \& Kallionpää, M. E. (2012) ReOrchestrating Game Drama. RMA Study Day Ludomusicology. Game Music Research. Approaches and Aesthetics, St Catherine's College, Oxford, UK, 16th April 2012.

Gaver, W. W. \& Mandler, G. (1987) Play it again, Sam. On liking music. Cognition and Emotion, 1, pp.259-282.

Grimshaw, M., Lindley, C.A. \& Nacke, L. (2008) Sound and Immersion in the First-Person Shooter. Mixed Measurement of the Player's Sonic Experience. Development, 1-7.

http://digitalcommons.bolton.ac.uk/gcct conferencepr/7 (retrieved 31 July 2012).

ljsselsteijn, W., de Kort, Y., Poels, K., Jurgelionis, A. \& Bellotti, F. (2007) Characterising and Measuring User Experiences. ACE Conference '07, Salzburg, Austria, 13-15 June 2007.

http:///rcm.com.umontreal.ca/Dufresne/COM6535/IJsselst eijn\%20et\%20al\%202007\%20Characterising\%20and\%2 OMeasuring\%20User\%20Experiences\%20ACE\%202007 \%20workshop.pdf (retrieved 16 June 2013).

Juslin, P. N. \& Laukka, P. (2003) Communication of emotions in vocal expression and music performance. Different channels, same code? Psychological Bulletin, 129(5), pp.770-814.

Juslin, P. N. \& Lindström, E. (2011) Musical Expression of Emotions: Modelling Listeners' Judgements of Composed and Performed Features. Music Analysis, Musical Expression of Emotions, 29(1-3), pp.334-364.

Klimmt, C., Hefner, D., Vorderer, P., Roth, C. \& Blake, C. (2010) Identification with video game characters as automatic shift of self-perceptions. Media Psychology, 13(4), pp.323-338.

Koster, R. (2005) Theory of Fun for Game Design. Paraglyph Press, Phoenix, AZ.

Lombard, M., Reich, R. D., Grabe, M. E., Bracken, C. C. \& Ditton, T. B. (2000) Presence and Television. The Role of Screen Size. Human Communication Research, 26(1), pp.75-98. 
Maasø, A. (2000) Synchronisieren ist unnorwegisch [Dubbing is not Norwegian]. Montage AV, 9(1), pp.147171.

Magliano, J. P., Dijkstra, K. \& Zwaan, R. A. (1996) Generating predictive inferences while viewing a movie. Discourse Processes, 22, pp.199-224.

Moore, J. D. (2010) The Impact of Visual-Music Interaction on Music Perception. The Influence of Agreement and Disagreement. Master Thesis at Baylor School of Music, Baylor, TX. USA.

https://beardocs.baylor.edu/xmlui/handle/2104/8043 (16 June 2013).

Nagel, F., Kopiez, R., Grewe, O. \& Altenmüller, E. (2007) EMuJoy. Software for continuous measurement of perceived emotions in music. Behavior Research Methods, 39(2), pp.283-290.

Örtqvist, D. \& Liljedahl, M. (2010) Immersion and Gameplay Experience. A Contingency Framework. International Journal of Computer Games Technology, $1-11$.

Petrini, K., Crabbe, F., Sheridan, C. \& Pollick, F. E. (2011) The Music of Your Emotions. Neural Substrates Involved in Detection of Emotional Correspondence between Auditory and Visual Music Actions. PLOS ONE, 6, 4. http://dx.plos.org/10.1371/journal.pone.0019165.pdf (retrieved 16 June 2013).

Poels, K., de Kort, Y. \& IJsselsteijn, W. (2007) 'It is always a lot of fun!' Exploring Dimensions of Digital Game Experience using Focus Group Methodology. Future Play 2007 Conference, New York, NY.

Popper, A. N. \& Fay, R. R. (1997) Evolution of the ear and hearing. Issues and questions. Brain, Behavior and Evolution, 50, 4, pp.213-220.

Quantic Dream (Developer) (2010) Heavy Rain. Playstation 3. Sony Computer Entertainment, Japan.

Ravaja, N., Gouveia, F. R., Biocca, F., Sacau, A., Jäncke, L., Baumgartner, T. \& Käncke, P. (2007) A Process Model of the Formation of Spatial Presence Experiences. Media Psychology, 9, pp.493-525.

Ravaja, N., Laarni, J., Kallinen, K., Saari, T., Salminen, M., Holopainen, J. \& Järvinen, A. (2004) Spatial Presence and Emotional Responses to Success in a Video Game. A Psychophysiological Study. Presence 2004. Proceedings of the Conference on Presence, Valencia, Spain, 13-15 October 2004.

http://www.temple.edu/ispr/prev conferences/proceeding s/2004/presence2004.pdf (16 June 2013).

Rocksteady (Developer) (2009) Batman. Arkham Asylum. PC-Windows, Xbox 360, Playstation 3. Eidos Interactive, UK.

Rocksteady (Developer) (2011) Batman. Arkham City. PC-Windows, Xbox 360, Playstation 3. Warner Bros. Interactive, USA.

Russell, J. A. (1980) A circumplex model of affect. Journal of Personality \& Social Psychology, 39, pp.11611178.

Sanders, T. \& Cairns, P. (2010) Time perception, immersion and music in videogames. Proceedings of the 24th BCS Interaction Specialist Group Conference, Dundee, Scottland, pp.160-167.

Spence, C. \& Driver, J. (1997) Audiovisual links in exogenous covert spatial attention. Perception \& Psychophysics, 59, pp.1-22.

Stevens, R. \& Raybould, D. (2012) Designing a game for music. Integrated design approaches for Ludic music and Interactivity. Oxford Handbook of Interactive Audio. Oxford University Press.

Tan, E. S. (1996) Emotion and the structure of narrative film. Film as an emotion machine. Lawrence Erlbaum, Mahwah, NJ.

Vitouch, O. (2001) When Your Ear Sets the Stage. Musical Context Effects in Film Perception. Psychology of Music, 29(1), pp.70-83.

Vorderer, P., Wirth, W., Gouveia, F. R., Biocca, F., Saari, T., Jäncke, L., Böcking, S., Schramm, H., Gysbers, A., Hartmann, T., Klimmt, C., Laarni, J., Ravaja, N., Sacau, A., Baumgartner, T. \& Jäncke, P. (2004) Development of the MEC Spatial Presence Questionnaire, MEC-SPQ. Report for the European Comission, IST Programme 'Presence Research Activites'.

Wassermann, K. C., Eng, K., Verschure, P. F. M. J. \& Manzolli, J. (2003) Live soundscape composition based on synthetic emotions. Multimedia, IEEE, 10(4), pp.8290.

Wingstedt, J. (2005) Narrative Music. Towards an Understanding of Musical Narrative Functions in Multimedia. http://pure.Itu.se/portal/files/199292/LTULIC-0559-SE.pdf (16 June 2013).

Wirth, W. \& Hofer, M. (2008) Präsenzerleben. Eine medienpsychologische Modellierung. [Presence Experience. A media psychological modelling approach] montage AV, 17(2), pp.159-175.

Wirth, W., Hartmann, T., Böcking, S., Vorderer, P., Klimmt, C., Schramm, H., Saari, T., Laarni, J., Ravaja, N., Gouveia, F. R., Biocca, F., Sacau, A., Jäncke, L., Baumgartner, T. \& Käncke, P. (2007) A Process Model of the Formation of Spatial Presence Experiences. Media Psychology, 9, pp.493-525.

Witmer, B. G. \& Singer, M. J. (1998) Measuring Presence in Virtual environments. A Presence questionnaire. Presence, Teleoperators and Virtual Environments, 7(3), pp.225-240.

Yamada M., Fujisawa N. \& Komori S. (2001) The effect of music on the performance and impression in a video racing game. Journal of Music Perception and Cognition, 7(2), pp.65-76.

Zbikowski, L. M. (1999) Musical Coherence, Motive, and Categorization. Music Perception. An Interdisciplinary Journal, 17(1), pp.5-42.

Zwaan, R. A. (1999) Situation models. The mental leap into imagined worlds. Current Directions in Psychological Science, 8, pp.15-18. 